Illinois State University

ISU ReD: Research and eData

Theses and Dissertations

$3-31-2020$

\title{
"but We Can Be Friends": An Analysis Of Turning Points In Platonic Friendships Among Former Significant Others
}

Desiree Hernandez

Illinois State University, dhern18@ilstu.edu

Follow this and additional works at: https://ir.library.illinoisstate.edu/etd

Part of the Communication Commons

\section{Recommended Citation}

Hernandez, Desiree, "'but We Can Be Friends": An Analysis Of Turning Points In Platonic Friendships Among Former Significant Others" (2020). Theses and Dissertations. 1235.

https://ir.library.illinoisstate.edu/etd/1235

This Thesis is brought to you for free and open access by ISU ReD: Research and eData. It has been accepted for inclusion in Theses and Dissertations by an authorized administrator of ISU ReD: Research and eData. For more information, please contact ISUReD@ilstu.edu. 


\section{"BUT WE CAN BE FRIENDS": AN ANALYSIS OF TURNING POINTS IN PLATONIC FRIENDSHIPS AMONG FORMER SIGNIFICANT OTHERS}

\section{DESIREE HERNANDEZ}

66 Pages

This study aims to understand the patterns of how romantic exes communicate, also known as post-dissolution communication. Specifically, the purpose of this qualitative analysis was to describe the functions of turning points individuals experienced in a platonic friendship with an ex-romantic partner. Three themes emerged from 13 in-depth interviews: framing distance as reparative, redefining boundaries, and providing ongoing support. The results provide insight into what turning points individuals experience during post-dissolution communication. KEYWORDS: post-dissolution communication, romantic history, post-dating relationships, semi-structured interviews, qualitative, thematic analysis 
"BUT WE CAN BE FRIENDS": AN ANALYSIS OF TURNING POINTS IN PLATONIC FRIENDSHIPS AMONG FORMER SIGNIFICANT OTHERS

DESIREE HERNANDEZ

\author{
A Thesis Submitted in Partial \\ Fulfillment of the Requirements \\ for the Degree of \\ MASTER OF SCIENCE \\ School of Communication \\ ILLINOIS STATE UNIVERSITY
}


Copyright 2020 Desiree Hernandez 
"BUT WE CAN BE FRIENDS": AN ANALYSIS OF TURNING POINTS IN PLATONIC FRIENDSHIPS AMONG FORMER SIGNIFICANT OTHERS

DESIREE HERNANDEZ

COMMITTEE MEMBERS:

Lindsey Thomas, Co-Chair

John R. Baldwin, Co-Chair

Phillip Chidester 


\section{ACKNOWLEDGMENTS}

Thank you to Dr. Baldwin and Dr. Thomas for agreeing to co-chair my thesis committee and for all your guidance throughout this process. Dr. Chidester, thank you for serving on my committee and for all your help and insights. It was an honor to work with all of you. It was because of you three that I managed to complete this thesis. I want to thank everyone that works in the School of Communication at Illinois State, I had a wonderful time in this graduate program because of you all. I also want to thank my parents for the support they gave me while I attended grad school. To my sisters, Alyssa and Tanya, thank you for always being there no matter what. Daniel, I am so lucky to have such a supportive fiancé while I was spending so much of my time writing this. I can't wait to see what the future has in store for us moving forward.

D.H. 


\section{CONTENTS}

Page

ACKNOWLEDGMENTS

CONTENTS

CHAPTER I: INTRODUCTION 1

CHAPTER II: LITERATURE REVIEW

Relationship Dissolution Patterns and Models 4

Relationship Dissolution Stages $\quad 4$

Trajectories of Relationship Dissolution $\quad 6$

$\begin{array}{ll}\text { Relationship Dissolution Communication } & 7\end{array}$

$\begin{array}{lr}\text { Post-Dissolution Relationships } & 8\end{array}$

Theorizing Post-Dissolutional Romantic Relationships 10

$\begin{array}{lr}\text { Turning Points } & 12\end{array}$

$\begin{array}{ll}\text { Social Exchange Theory } & 13\end{array}$

$\begin{array}{ll}\text { The Present Study } & 17\end{array}$

$\begin{array}{ll}\text { Conclusion } & 19\end{array}$

$\begin{array}{ll}\text { CHAPTER III: METHODS } & 20\end{array}$

$\begin{array}{ll}\text { Data Collection } & 20\end{array}$

$\begin{array}{ll}\text { Participants } & 22\end{array}$

$\begin{array}{ll}\text { Data Analysis } & 22\end{array}$

$\begin{array}{ll}\text { Conclusion } & 23\end{array}$

$\begin{array}{ll}\text { CHAPTER IV: RESULTS } & 24\end{array}$

$\begin{array}{ll}\text { Framing Distance as Reparative } & 24\end{array}$ 
Redefining Boundaries

$\begin{array}{ll}\text { Providing Ongoing Support } & 37\end{array}$

$\begin{array}{ll}\text { Conclusion } & 43\end{array}$

$\begin{array}{ll}\text { CHAPTER V: DISCUSSION } & 44\end{array}$

Implications of the Results $\quad 44$

$\begin{array}{ll}\text { Directions for Future Research } & 50\end{array}$

$\begin{array}{ll}\text { Strengths and Limitations } & 50\end{array}$

$\begin{array}{ll}\text { Future Research } & 51\end{array}$

$\begin{array}{ll}\text { Summary } & 52\end{array}$

$\begin{array}{ll}\text { REFERENCES } & 54\end{array}$

$\begin{array}{ll}\text { APPENDIX A: RESEARCH BOARD RECRUITMENT } & 60\end{array}$

$\begin{array}{ll}\text { APPENDIX B: EMAIL RECRUITMENT } & 61\end{array}$

APPENDIX C: INFORMED CONSENT

$\begin{array}{ll}\text { APPENDIX D: DEMOGRAPHICS QUESTIONNAIRE } & 64\end{array}$

APPENDIX E: PARTICIPANT DEMOPGRAPHICS 65

APPENDIX F: INTERVIEW PROTOCOL 66 


\section{CHAPTER I: INTRODUCTION}

It is important for interpersonal research to capture all aspects of personal relationships. It is problematic when researchers categorize the patterns of intimate relationship into cycles or stages because this notion emphasizes that communication ends between two romantic partners at a certain point -at relationship dissolution (Koenig Kellas, Bean, Cunningham, \& Yun Cheng, 2008). Thus, this generates a gap in research on post-dissolution romantic relationship communication. Even though individuals report that they speak with or are friends with their ex (Koenig Kellas, 2006; Koenig Kellas et el., 2008; Schneider \& Kenny, 2000), post-dissolution communication is not widely researched. With that, further research on post-dissolution romantic relationship communication makes information available that helps others understand postdissolution communication patterns and the significance of platonic friendships.

Studies about post-dissolution communication are likely to bring profound discoveries, highlighting unique interactions between exes. Previous research on post-dissolution communication focused on divorced couples (Hogerbrugge, Komter, \& Scheepers, 2012; Koenig Kellas, 2006), implying that only couples that were once married have reasons to continue communicating after breaking up. These studies could be improved by including more diverse samples because some pre-martial couples have numerous, valid reasons to continue having a post-dissolution relationship. Research that includes pre-martial couples discover how postdating relationships transform.

I believe it is important for research to capture the perceptions of individuals that continue to feel close to or have some form of a relationship with a former romantic partner and those who have formed a platonic friendship with an ex. I am interested in the ways exes navigate the implications of break-ups on their relationships and the ways exes interact. To 
capture the communicative process between friendly, platonic exes, I incorporate using social exchange theory (SET) and turning points. SET closely examines exchanges between individuals. Turning points are traditionally used to plot significant moments throughout a relationship, but I use them as a tool to understand a series of conversations in this study. The research questions for this study are, "What functions as turning points when people experience a platonic relationship with a former significant other?" and "What types of turning points do partners in platonic relationships with former significant others perceive as positive or negative?" The purpose of this study aims to better understand the turning points in platonic friendships between ex-romantic partners.

I used semi-structured, in-depth one-on-one interviews to conduct this study. The goal of this study was to create a list of themes that emerge during the interview protocol with the participants. According to the participants that from this study, they feel as though many people do not remain friends with an ex. For nearly all of them, the conducted interviews were the only time they spoke about the relationship they have with their exes. This study's results begin to explain the functions during post-dissolution communication include placing respectful boundaries between exes, reparative processes, and supportive resources. 


\section{CHAPTER II: LITERATURE REVIEW}

In previous studies, interpersonal researchers rarely explore beyond the point of dissolution in intimate relationships. Past studies positioned that communication ends between former romantic partners when their intimate relationship terminates (Busboom, Collins, Givertz, \& Levin, 2002). Other previous research about post-dissolution communication only applies to divorced couples (Hogerbrugge, Komter, \& Scheepers, 2012; Koenig Kellas, 2006). Future studies about post-dissolution relationships are likely to provide insights into the unique interactions between ex-partners. In the present chapter, I review relationship stages established by previous research. Then, I provide an introduction to post-dissolution communication and explain the research gap from the perspective of pre-martial couples that continue a relationship after breaking-up.

Relationships, including friendships, intimacy, and family, are meaningful for individuals. Relationships fulfill the need for human connection, which is essential to well-being (Busboom et al., 2002). Specifically, personal relationships provide opportunities for individuals to be around and enjoy the company of others. No matter the type of relationship, friendships and romances provide individuals with valued resources (Busboom et al., 2002). This highlights the social significance of relationships for individuals. Currently, friendships and romantic

relationships are considered separate phenomena (Altman \& Taylor, 1973; Duck 1986; Knapp \& Vangelisti, 1992). I argue that friendships and romantic relationships should intertwine in interpersonal communication research. Such research challenges the notion that former romantic partners cannot form a meaningful friendship after breaking up. The results from further research on post-dissolutional communication illustrate what occurs beyond the point of dissolution. 
Further, research about post-dating relationships captures data on romances that are redefined into friendships and the process of transforming former partners into friends.

\section{Relationship Dissolution Patterns and Models}

First, reviewing what is already known from previous studies is important to understand post-dissolutional communication because terms and findings are referenced throughout this study. There are many fundamental frameworks about relationship dissolution established by previous researchers. In previous work, scholars provide insight on the stages of intimate relationships (Altman \& Taylor, 1973; Knapp \& Vangelisti, 1992), strategies used regarding breaking up (Baxter, 1984), communication styles during the dissolution process (Duck, 1982; Rollie \& Duck, 2006), and how break-ups affect the individuals involved (Goffman, 1952). This review of research on the relationship dissolution process provides a stable foundation and direction for future research on post-dissolutional romantic relationships (PDRs). Then, I introduce post-dissolutional communication and overview existing studies on PDRs to explain what is already known about post-dating relationships and communication.

\section{Relationship Dissolution Stages}

Galvin and Wilkinson (2006) define interpersonal communication as ongoing, voluntary interactions that occur between two people. With time, people feel deep and unique connections with friends and romantic partners and the perception of a relationship forms, evolving into a sense of a significant relationship (Galvin \& Wilkinson, 2006). Romantic relationships are a form of interpersonal connection that fulfill individuals' desire to feel close with others (Baumeister \& Leary, 1995). Yet, not all romantic relationships last forever, making it likely that people experience relationship dissolution. 
The stages of intimate relationships provide information on how relationships form and deteriorate. Knapp and Vangelisti (1992) created the staircase model that describes how growing relationships go through five stages. These stages are (1) initiating, (2) experimenting, (3) intensifying, (4) integrating, and (5) bonding. Also, according to Knapp and Vangelisti, relational partners go through a process in which they further distance themselves from each other demonstrated by the stages (1) differentiating, (2) circumscribing, (3) stagnating, (4) avoiding, and (5) terminating. Differentiating means individuals in the relationship realize how different they are from each other and drift. Often the circumscribing stage consists of more arguing, leading couples to feel confused and disconnected from each other. The stagnating stage explains how couples begin to have shorter conversations or they avoid communicating because they predict the outcome of doing so is unpleasant. After stagnating, couples enter the avoiding stage, in which they try to avoid each other and distance themselves from the relationship, leading to vague interactions about general subjects. Finally, couples reach the terminating stage after they realize they are unhappy together, and they begin to move forward in life without each other. This model is based on the framework that relationships go through a formation process and as the process is undone, they begin to fall apart and end.

Additional research conceptualizes how relationships form and the reason they sustain over time. Altman and Taylor's (1973) social penetration theory (SPT) predicts relationship growth and how people bond based on self-disclosure. They compare information about a person to an onion's layers. As people get to know each other, they disclose more intimate details about themselves, similarly, to peeling away an onion. However, the alternative of withholding and concealing information from an intimate partner causes de-penetration. De-penetration is the opposite process and occurs when people withdraw from each other, causing distance in 
relationships (Altman \& Taylor, 1973). Knapp and Vangelisti (1992) and Altman and Taylor (1973) believe that people build relationships in similar ways. Their frameworks place emphasis on the ways relationships change and offer an order of the various stages people go through. Alike, Knapp and Vangelisti (1992) and Altman and Taylor (1973) predict the outcomes of relationships by determining how relationships form and terminate.

\section{Trajectories of Relationship Dissolution}

Further research clarifies how people initiate the dissolution process. For example, Baxter (1984) investigated the strategies people used when they initiate a break-up, generating relationship dissolution trajectories. According to Baxter, break-ups are complex processes that include six main features. The first feature explains if relationship dissolution occurs due to gradual relationships problems, "incrementalism," or suddenly due to a "critical incident." Second, people reach the decision to end their intimate relationship whether it is unilateral, where one party in the relationship desires to break-up, or bilateral, where the break-up is mutual. Another feature of break-ups includes if the actions used to execute it are direct or indirect. The fourth feature captures if the speed of the break-up is rapid or protracted, and this depends on the reaction of the person that is broken up with. In the fifth feature of relationship dissolution, some people may attempt to repair their relationships because they do not accept ending the relationship, or they may decide not to repair it. The final feature is if the relationship ends or if the relationship continues in the same form or in a redefined, different form. To emphasize the importance of studying break-ups, Baxter's research illustrates that relationship dissolution is a process that follows a large number of trajectories, thus how much interpersonal relationships fluctuate. It is important for research to allow for variations in communication, because it includes a wider range of phenomena. 


\section{Relationship Dissolution Communication}

When relationships end, people communicate messages of disapproval and dissatisfaction to their partners. Duck's (1982) four stages of relationship dissolution capture the components of how people communicate break-up messages. First, the intrapsychic stage is where one partner is unhappy and wants to proceed with breaking up after they internally assess the options for their relationship. Then, the initiating partner confronts the other partner about breaking up in the dyadic phase, during this phase the couple discusses breaking up. Then in the social phase, the partners compose a narrative of the break-up and decide how to announce it to others like peers, family, and social networks. Last, the former romantic partners process the break-up, make sense of it, and justify why their relationship ended during the grave-dressing stage. In 2006, Rollie and Duck modified the model and added a fifth stage, the resurrection phase, where people realize what they learned from their previous relationship then prepare themselves for new relationships. Each of the stages capture the changes in communication patterns when people experience break-ups.

Other research on relationship dissolution focuses on how people make sense of a breakup and how they manage the transition of redefining an existing relationship. Once, the term "cooling the mark out" just applied to the method con men used when the person from whom they scammed money, the mark, threatened to report the incident to authorities (Goffman, 1952). Con men use this strategy to prevent confrontation from law enforcement by getting their victims to accept an inevitable loss. However, Goffman applies cooling out to other social situations. The "cooling out" metaphor in intimate relationships suggests an initiator of relationship dissolution "softens the blow" of a break-up in an effort to help the receiver accept the situation. This point suggests a person initiating a break-up talks their intimate partner through the dissolution 
process. For example, Alex may want to break-up with Emily, but Emily does not want to end their relationship. According to Goffman, Alex makes an effort to encourage Emily to agree with the decision of ending their relationship. This idea alludes to how individuals redefine an intimate relationship during a break-up. "Cooling out” occurs when an individual explicitly communicates to their partners during the process of a break-up. This framework begins to describe how romantic partners communicate before the point of dissolution and redefine their relationship.

\section{Post-Dissolution Relationships}

It is clear why there is an abundance of studies examining relationship dissolution, because break-ups are a complex process (Baxter, 1984) that affects individuals in numerous ways (Goffman, 1952). Although, relationship dissolution stages (e.g., Altman \& Taylor, 1973;

Duck \& Rollie, 2006; Knapp \& Vangelisti, 1992) and the trajectories of relationship dissolution (Baxter, 1984) do not include continued friendships between former partners. This gap in literature generated an assumption among relationship theorists that relationship dissolution leads to the abrupt, permanent separation of former romantic partners (Busboom et al., 2002).

There is a possibility for former romantic partners to maintain contact after a break-up, referred to as, post-dissolution communication. Post-dissolution communication is "the interaction that takes place between former partners after the break-up of a romantic relationship" (Koenig Kellas, 2006, p. 282). Little is known about former romantic partners who continue to communicate after breaking up (Koenig Kellas, 2006; Schneider \& Kenny, 2000). Still, there are many reasons people chose to keep in contact with a former intimate partner, and many individuals report continuing to speak to their former significant other after the point of relationship dissolution (Koenig Kellas, 2006; Koenig Kellas et el., 2008; Schneider \& Kenny, 
2000). Previous studies found that individuals have relationships with ex-partners because they want to rekindle a romance with a former intimate partner (Kaplan \& Keys, 1997; Schneider \& Kenny, 2000) and that friendships are more likely after a break-up if the partners were friends to begin with (Metts, Cupach, \& Bejlovec, 1989). Koenig Kellas (2006) found former romantic partners that continued to communicate indicated the interactions assisted them while they coped with identity loss and the break-up itself. Other studies found similar results on PDRs and the impact they have on communication styles between former intimate partners.

There are advantages and disadvantages in situations where former intimate partners continue to communicate after ending their romantic relationship. Foley and Fraser (1998) found that people maintained relationships with exes out of necessity or convenience. Lannutti and Cameron (2002) examined a heterosexual and homosexual sample and found that relationship uniqueness, hope for romance, or participants that liked their former partner were positive indicators of PDR for same-sex and opposite-sex partners. Other predictors of PDR quality included time since breaking up and relationship length. In another study, participants reported that post-dissolutional friendships had lower quality than the quality of platonic friendships (Schneider \& Kenny, 2000). When researchers conduct studies on PDRs, participants speak of experiencing rewards when sustaining communication with an ex-intimate partner.

Koenig Kellas (2006) conducted a study of post-dissolutional communication through participants' stories of relationship dissolution. They investigated the post-dissolutional narratives people told, bringing the benefits of narratives, such as sense-making and the agency of reciting their version of a story. Koenig Kellas (2006) found five different types of communication styles used following a break-up. The different styles include (1) positive communication, (2) occasional/circumstantial communication, (3) rare, awkward, or negative 
communication, (4) absence of communication, and (5) no mention of communication. Positive communication occurs when former intimate partners are kind to each other and may stay or want to remain friends after breaking up. Next, occasional or circumstantial communication describes situations where routines or common activities cause ex-partners to be around each other interactions due to sexual encounters. Unsuccessful attempts at communication, such as when an individual felt obligated to continue speaking to their ex, as well as ambiguous or hazardous communication, were categorized as rare, awkward, or negative communication. Absence of communication referred to no communication after breaking up or only communication over electronic media. Last, responses from participants that did not mention having any communication with previous partners created the final communication style, no mention of communication. Keonig Kellas' types of communication in PDRs capture how differently people interact with former significant others.

\section{Theorizing Post-Dissolutional Romantic Relationships}

Usera (2018) states that an abundance of research focuses on the communication that occurs between partners before and during the dissolution process but not after. Theoretical frameworks like Baxter's (1984) trajectory of dissolution interactions and Duck's (1982) stage models state that break-ups are events where romance ends and so does any type of relationship. Baxter (1984) posits that intimate partners only interact during the dissolution phase of a relationship and they sustain contact to while attempting to repair a romantic relationship. This limits why former intimate partners have a relationship and communicate after breaking-up. The grave-dressing and resurrection phase of Rollie and Duck's (2006) stages of dissolution describe break-ups as events where individuals must construct narratives to benefit their well-being and require them to grow from the experience to move on. Duck's (1982) model assumes that 
breaking up brings people to take massive measures to recover, which negatively frames postdating relationships. For example, if people experience a brief, romantic relationship that ended on mutual terms, then they may not need to process through the grave-dressing or resurrection phase long before they form new relationships, including one with their former partner. Baxter's (1984) and Duck's (1982) frameworks do not describe what relationship cycles are like beyond break-ups.

In a similar way, Altman and Taylor (1973) and Knapp and Vangelisti (1992) do not explain what occurs beyond relationship dissolution, there is a point where the cycle ends. Social penetration theory supports relationships forming on the basis of self-disclosure (Altman \& Taylor, 1973). The contrast of ending a relationship involves de-penetration where people in relationships drift apart. Eventually, former partners only know superficial information about each other, according to this process. This may not be true in all cases after people break-up, especially in situations where they continue some form of a relationship. Knapp and Vangelisti (1992) believe that relationships form and terminate in a mirroring process similar to SPT (Altman \& Taylor, 1973). They predict post-dating communicative behavior is "narrow, difficult, rigid, awkward, and hesitant" (Knapp \& Vangelisti, 2006, p. 272). These frameworks imply the event of a break-up ceases any form of relationship between two former intimate partners and ends all communication. This infers that intimate relationships are a linear process, and there is nothing more to discover about people who communicate after relationship dissolution, because nothing occurs after a certain point in the cycle. Other interpersonal communication scholars argue breaking up is not the end of a relationship but the end of an identity for couples, instead (e.g., Usera, 2018). This calls for more research on former partners 
that continue to communicate and requires theoretical frameworks to extent past the point of relationship dissolution (Koenig Kellas et al., 2008).

\section{Turning Points}

Turning points (TPs) provide insight into the transformation, history, and development of relationships (Baxter \& Pittman, 2001). Baxter and Bullis (1986) state that TPs are events that, over time, critically change relationships. They emphasize that turning points supply a lens to analyze communication and meaning during relationship development. TP analysis allows researchers to gain an understanding of the changes and patterns that occur throughout a relationship. By exploring the TPs overall, research captures what participants believe to be profound turning points in their lives and relationships. Studying TPs provides an understanding of the process of relational maintenance and about the decisions people make following relationship dissolution. To understand the nature of post-dissolutional communication through former partners that are friends, turning points are a suitable framework for this context.

Turning points represent important aspects of interpersonal relationships. TPs reveal the various implications of a personal relationship's history and capture the impact on the involved individuals. So accordingly, TPs reproduce people's communication practices of remembering, how parties interpret the history and meaning throughout a relationship (Baxter \& Pittman, 2001). Turning points are a way for people to purposely recall a relationship's past and present events and if the events bring positive or negative memories. Past and present TPs lead to understanding relationships in great detail because they ask participants for significant events in retrospect (Parcell \& Maguire, 2014). Specifically, TPs capture how relationships change, making them ideal for conceptualizing the transition from being in a romantic relationship to 
remaining friends with a former partner. Research that incorporates TPs unpack the significance of communicative events in interpersonal relationships.

Interpersonal communication researchers used TPs in previous studies as a framework to examine romantic and platonic relationships. For example, the researchers asked their participants to use turning points to remember significant events that developed their romantic relationships (Baxter \& Pittman, 2001). Another study used TPs to describe the changes during on-again/off-again romantic relationships (Dailey, LeFebvre, Crook, \& Brody, 2016). Koenig Kellas et al. (2008) used TPs to analyze narratives about post-dissolutional romantic relationships. Focused on the transition process, a study employed turning point analysis to approach friendship development and termination (Johnson, Wittenberg, Haigh, Wigley, Becker, Brown, \& Craig, 2004). Data acquired through TP analysis generate results that extend the literature on post-dissolutional communication.

In the present study, the focus is on the events that follow a break-up to forming a friendship between previous romantic partners, because there is value to investigating how individuals remember significant events throughout a relationship (Baxter \& Pittman, 2001). Though the traditional use of turning points encompass much of this study, I introduce a new way to incorporate them into research. I broaden the use of TPs to understand the communicative processes between exes, and I consider a break-up as the main turning point. Instead of framing this study around plotted turning points, I focus on the described processes that occurred over time, after a break-up, as communicative interactions constructed the exes' friendship.

\section{Social Exchange Theory}

According to the social exchange process (Homans, 1958; Thibaut \& Kelley, 1959), relationships result in social costs and benefits. Relationships that result in benefits develop into 
a high-quality bond between individuals. Social exchange theory provides a stable framework to conduct the present study to understand the PDR process. SET (Homans, 1958; Thibaut \& Kelley, 1959) is based on the interactions in relationships. The theory states a person's individual actions affect the course of a relationship. Homans (1958) and Thibaut and Kelley (1959) created social exchange theory on the premise that people engage in relationships when they believe the relationship brings them benefits, for a self-serving bias. What drives a person's actions are the perceived costs and rewards of decisions during relationships (Homans, 1958; Thibaut \& Kelley, 1959). Costs are factors that inhibit or deter a behavior in a relationship (Thibaut \& Kelley, 1959). Positive relational elements are rewards, such as acceptance, security, support, pleasure, satisfaction, intimacy, gratification, and companionship (Homans, 1958; Thibaut \& Kelley, 1959). To calculate worth in relationships, SET predicts that outcome satisfaction equals the rewards minus the costs. Theoretically, if the worth is calculated to be a positive number then people perceive their relationships are worth the costs. However, people do not deem their relationships are worth the effort if they get a negative amount after subtracting the costs from the rewards. SET is an ideal theoretical guide as individuals consider being friends with a former romantic partner if they evaluate the rewards and costs associated with PDRs.

Social exchange theory is based on the premise that social interactions are exchanges between two individuals (Homans, 1958; Thibaut \& Kelley, 1959). SET is rooted in the concept of profit-motivated, economic exchanges but applies to social situations. Typically, social situations are voluntarily and occur between at least two people (Stafford, 2008). Economic exchanges are described as transactions that typically involve goods and services exchanged for money or bartered for other goods and services. Even when this logic is applied to social situations, SET explains and predicts that people have their own best interest in mind during 
interactions with others and are seeking to maximize rewards and minimize costs (Stafford, 2008). Thus, basic assumptions of SET include (Stafford, 2008): Behavior is a series of social interactions, individuals want more rewards than costs, and individuals experience feelings of obligation after receiving rewards from others. Therefore, SET explains people's preferences while those people interact with others, and these concepts make it possible to investigate postdating relationships in future research.

It is important to review how social exchange theory conceptualizes communication and recognize the theory's strengths and weaknesses. Stafford (2008) explains three ways in which social exchanges conceptualize communication: (1) "Exchanges occur through communication and communication is used as a tool, (2) communication is the reward or the cost in interactions, (3) social exchanges have symbolic, communicative value" (p. 381). Three criticisms of SET include: Close, long term relationships do not occur on the basis of social exchanges, people are not constantly searching for rewards over costs making them unlike the "self-serving" basic assumption, and people's decisions about social exchanges are not as rational as SET portrays (Stafford, 2008). Despite its weaknesses, SET is heuristic and parsimonious. Over time, SET generated a significant amount of research (Stafford, 2008). For example, Altman and Taylor (1973) draw on SET when they explain self-disclosure. SET's three basic assumptions are simple, making it parsimonious. In all, SET is a post-positive theory used to explain why people engage in the interactions they have with others, an ideal framework to help explain PDRs. Strengths and weakness aside, I plan to use SET to guide this study because of its use in previous interpersonal studies that sought answers about relationships

Social exchange theory is used to provide a theoretical understanding a plethora of situations involving interpersonal relationships. Hand and Furman (2009) used SET to examine 
platonic friendships, between opposite sex and same sex participants, and heterosexual romantic relationships among adolescent, high school seniors. They found opposite-sex friendships consists of costs and rewards different from same-sex and romantic relationships, emphasizing the importance of different types of relationships and the unique benefits they bring. Results in a study about romantic relational outcomes concluded that people perceived interactions where their partners overtly sought out information about emotional baggage as rewarding (Frisby, Sidelinger, \& Booth-Butterfield, 2015). Another study tested the effects of communication strategies disclosing relational betrayal and found that offenders in the relationship were more likely to be forgiven when they apologized, promised to change, and stated they valued the relationship (Ferrara \& Levine, 2009). In a study examining post-dissolutional friendship quality, the researchers found that barriers from a social exchange perspective predicted negative friendship quality while frequency of resources leads to positive friendship quality (Busboom et al., 2002). SET captures complicated situations in relationships and explanations for people's actions and decisions. This is applicable to future research about situations involving individuals that continue to communicate post relationship dissolution.

Previous studies using SET provide discoveries about people's actions throughout relationships and lead to new information about friendships and romances, positioning SET as a suitable lens to conduct this study and find relevant results on PDRS. Using social exchange theory, this study analyzes the perceived costs and benefits of PDRs, assuming the rewards for those who choose to maintain relationships with ex-partners outweigh the costs. The anticipated results answer the calls for future research on PDRs: going beyond the break-up (Rollie \& Duck, 2006) and gaining perspectives from pre-martial exes that communicate (Koenig Kellas et al., 2008). Thus, the present study relies upon SET to find why people engage in PDRs for reasons 
other than getting back with their ex-partner for romantic intent (Kaplan \& Keys, 1997;

Schneider \& Kenny, 2000). The results of this study might show positive aspects of messages in post-dissolution relationships, through the responses collected from participants' personal experiences.

\section{The Present Study}

Up to this point, it is evident that romantic relationships and friendships are important to individuals. Often, people become close with their significant other and may refer to them as their best friend (Schneider \& Kenny, 2000). The opposite of developing an intimate relationship is the process of terminating one. After breaking up, people redefine the relationship with the former partner they were once close to. Research demonstrates that going through a break-up or relationship dissolution leads to negative outcomes (VanderDrift, Wilson, \& Agnew, 2012), like experiencing trauma (Frost, Rubin, \& Darcangelo, 2016; Sprecher, Felmlee, Metts, Fehr, \& Vanni, 1998; Usera, 2018). Previous research concludes that narrative meaning making (Frost et al., 2016), compassionate break-up strategies (Sprecher, Zimmerman, \& Fehr, 2014), and explicit communication between partners (Dailey, Rossetto, McCracken, Jin, \& Green, 2012) make the transition into singlehood a more positive one. Still, a gap exists researching the how people sustain communication with a former intimate partner following relationship dissolution.

Researchers' focus on relationship formation and dissolution calls for more studies that extend past the point of dissolution, this direction makes the current study's topic unique. Past studies about PDRs share insight on how complex PDRs are and lead to the topic of the cycles of intimate and platonic relationships. Rollie and Duck (2006) call for future research to look at communication beyond the break-up. However, previous research on post-dissolution relationships focuses on divorced couples significantly more than pre-martial couples 
(Hogerbrugge et al., 2012; Koenig Kellas, 2006). It is worthwhile to continue examining the perspective of pre-martial couples who continue a relationship after a breaking up, according to Koenig Kellas (2006). In their study, Koenig Kellas et al., (2008) state that there are couples who voluntarily redefine their relationship following dissolution, generating a new, different connection between individuals. These types of connections are important to the individuals that sustain them. More research on this topic gives people a voice and allows them to tell about their friendships with a former partner after the point of dissolution. There are more insights for research on non-martial couples that communicate after dissolution yet to be discovered. Koenig Kellas et al. (2008) call for post-dissolution research to collect data from both participants after ending an intimate relationship. The current study aims to answer some of these calls for future research with a pre-martial sample, but lacks perspectives from both participants in the relationship.

Given the importance of closeness from connections in romantic relationships, it makes sense to investigate the process when people maintain friendships with their exes. After breaking up, former couples might decide to redefine their relationships as friendships because of the interpersonal connection they continue to share (Busboom et al., 2002). This calls for more insight into post-dating relationships to fill the gap of research on post-dissolution relationships. This study seeks to discover more about PDRs and the communication that occurs between former intimate partners. Therefore, I ask the following research questions:

$\mathbf{R Q}_{\mathbf{1}}$ : What functions as turning points when people experience a platonic relationship with a former significant other?

$\mathbf{R Q}_{2}$ : What types of turning points do partners in platonic relationships with former significant others perceive as positive or negative? 


\section{Conclusion}

This study seeks to investigate the turning points in relationships between two exes that have remained friends after relationship dissolution, since this topic is not widely researched. To achieve the purpose of this study, the next chapter outlines a method that asks participants to recall the significant experiences that impacted and transformed their relationships after a breakup. 


\section{CHAPTER III: METHODS}

Individuals' experiences with post-dissolutional romantic relationships are not commonly studied; research on this topic is likely to provide new information about interactions between ex-partners. The previous chapter discusses key terms about relationship stages and identifies the gap of research missing about pre-martial couples that continue a relationship after breaking up. The purpose of this present study is to understand individuals' experiences with postdissolutional romantic relationships better. To answer the research questions, "What functions as turning points when people experience a platonic relationship with a former significant other?" and "What types of turning points do partners in platonic relationships with former significant others perceive as positive or negative?", I turn to qualitative methods of data collection and analysis. Qualitative research methods can help people describe their relational bonds and how they maintain and transform them (Lindlof \& Taylor, 2011). Thus, I plan to use a semi-structured protocol to interview participants. Qualitative interviews are an appropriate method of data collection for this study because interpersonal relationships are complex, and the study aims to understand the nuanced experiences of post-dissolutional interactions.

\section{Data Collection}

I recruited participants utilizing convenience and snowball sampling. Initial recruitment took place via the research board in the Communication department at a large midwestern university (see Appendix A). Additional searching for participants targeted students that receive campus wide recruitment messages through The University's email accounts (see Appendix B). The Institutional Review Board (IRB) granted approval for this study prior to the interviewing process. Potential participants contacted me via email if they were interested in the study. If the participant confirmed they were at least 18 years of age, indicated they were friends with a 
former romantic partner, and were willing to participate and to be audio recorded, then I scheduled an interview with them via email. Before I began the interviews, I went over the informed consent form to reiterate confidentiality (see Appendix C), and I asked the participants to fill out a questionnaire (see Appendix D) to collect their demographics. I asked the participants for their personal pronouns and so I could reference their gender accordingly in the analysis portion of the results. Some of the participants received class credit, extra credit, or no credit for being a part of this study. I conducted interviews until I reached saturation, a point in the research process where new information no longer emerges from the data analysis (Lindlof \& Taylor, 2011).

I used a semi-structured interview protocol to acquire data (Rubin \& Rubin, 2012). The interview protocol (see Appendix F), focused on the participants' responses about the turning points they experienced in a post-dissolutional relationship. Prior to capturing their responses, I defined a turning point to the participants as "a transformative event that alters a relationship in some important way, either positively or negatively" (Baxter, Braithwaite, \& Nicholson, 1999, p. 294). In the form of open-ended questions, I asked the participants to share their personal accounts of turning points in their post-dissolution relationship, and this allowed them to discuss their answers and with as much or as little detail they desired to provide. In the first section of the interviews, the questions focused on having the participants speak about the context of their interactions with their exes before, during, and after their break-ups. Then, I defined turning points to the participants and asked them to elaborate on their experience with post-dissolution communication in the second half of the interviews.

The duration of the interviews was between 30 and 60 minutes, lasting an average of about 38 of minutes. After collecting data, I manually transcribed the recorded interviews for 
further analysis and deleted them after transcription. I changed all the participants' and their exes' names to pseudonyms to maintain confidentiality. The transcribed interviews generated 70 single-spaced pages of text.

\section{Participants}

I conducted qualitative interviews with 13 participants (see Appendix E) throughout this study. Six females, five males, and two non-binary individuals consented to be interviewed for the study. Eleven of the 13 participants indicated their race was Caucasian, while one was Black or African American and the other was Asian. Five of the participants were 19 years old, the youngest of the sample, and the eldest participant was 48 years old. In terms of sexual orientation, eleven participants said they were straight, one said they were queer, and another said they were bisexual. Of the participants, ten specified they were single and the other three were married. Participants reported their romantic relationships lasted an average of 13 months, ranging from 3 months to 36 months ( 3 years). Also, the participants reported the time since the break-up with their ex ranged from 5 months to 264 months (22 years), generating an average of about 53 months. The two required criteria to participate in this study was being over the age of 18 and to indicate having a friendship with a previous romantic partner.

\section{Data Analysis}

I used the transcribed interviews to conduct a qualitative, thematic analysis of turning points in the process of remaining friends with a former partner following relationship dissolution. Thematic analysis allows insight into participants' experiences and how they construct reality (Braun \& Clarke, 2006), and promotes a thorough interpretation on the data set about post-dissolutional relationships. First, I familiarized myself with the data by reading and rereading the data consisting of the mentioned turning points and communicative transitions. 
Second, I coded the data to identify key ideas in the transcriptions relevant to the research questions. Then, I broke the ideas into units using open coding. Next, I collapsed units that overlapped into broader categories and subcategories of themes. After generating broad categories, I refined the themes to check if the data is accurately portrayed using level one and level two reviewing. In the following step, the I listed and defined each identified theme.

Also, I conducted a content analysis on each unit of analysis to determine the directionality of the turning points. The directionality identifies whether the type of turning points the participants provided to be categorized as positive, negative, or neutral. I assembled a codebook using SET to guide my decision to code and categorize the units of analysis. In the last step, I created a report that detailed every theme and the units that correspond to each theme, and I listed the directionality of the turning points. I conducted a member check to verify the results from the thematic analysis and content analysis to increase the credibility of the findings to the original participants. I emailed the report of the listed and defined themes and types of turning points to all of the participants, to ensure the open-coding analysis accurately represented the dataset (Lincoln \& Guba, 1985). Eight of 13 participants responded, and each of them confirmed that the dataset accurately represented their views.

\section{Conclusion}

The goal of this study was to create a typology of the themes that emerged from the turning points that the participants reported from their post-dissolutional romantic relationships. Semi-structured interviews allowed the participants to frame their experiences with open-ended answers. The findings generated from the methods section are analyzed in the next chapter. 


\section{CHAPTER IV: RESULTS}

This study investigates post-dissolution interactions and seeks new information about the ways exes communicate with each other. In the literature review, I identified the gap of research on pre-martial exes that continue a relationship after breaking up by referring to previous, applicable studies. I explained how I conducted interviews with human subjects for a qualitative analysis in the previous chapter.

Within this chapter, to address $\mathrm{RQ}_{1}$, which asks what functions as turning points in postdissolution communication and $\mathrm{RQ}_{2}$, regarding the directionality of the mentioned turning points, my qualitative analysis identified three themes that emerged from the participants' talk and how they described post-dissolution communication while in a current platonic relationship with an ex-romantic partner. The three themes I identified were framing distance as reparative, redefining boundaries, and providing ongoing support. I use various quotes from participants to illustrate the theme, how they described post-dissolution communication, and if they viewed their turning points as positive, negative, or neutral in the interviews in the following sections.

\section{Framing Distance as Reparative}

A number of participants indicated that they experienced becoming friends with their former significant other after a major change such as moving away, changing schools or careers, or moving onto new intimate relationships. Framing distance as reparative is a theme consisting exclusively of turning points that created distance between individuals and their respective exes that later altered the dynamic of their relationship, shifting from intimate to platonic.

Kylie, like a number of other participants, talked about the transition to college as a turning point. Kylie was upfront with her then boyfriend about how leaving for college was a turning point that would change their relationship. These pending changes resulted in her 
wanting for them to go their separate ways due to graduating high school and going to different colleges. She described going through a period of positive growth, even though her now-exboyfriend did not receive the news about the break-up well, which resulted in them becoming friends. Kylie explained:

But he came around to it, and he was fine with it, just being friends. It was weird for a while like a month or two after the break-up. Like, if we were out, we wouldn't really talk that much, then he got over it and we were pretty much just friends ever since.

Kylie goes into detail how the break-up was a good thing by saying, "I feel like actually breaking up was like the best. I think we work way better as friends, than we did when we were together, so I think that was like the best thing we could've done.” Kylie describes how the turning points she experienced were ultimately positive, because she learned how to navigate a break-up during a busy time when she experienced a lot of change, and still ended up becoming friends with a former partner who did not accept the circumstances at first.

The transition to college was also a major turning point for Jackie and her then boyfriend, because it helped them decided what direction to take their relationship. Jackie said:

'Cause we're both choosing where to go to school. And I was like, sorry no offense, you weren't going to be a major decision of like where I end up at school.' And he felt the same way so like it wasn't anything negative. It was just like, hey, like what are we really doing right now? Like, we both kind of just put it on hold and needed to figure our individual lives out. Then, we could maybe come together and work better later. But for the time being, we just kind of sat down and talked, like OK maybe this isn't working in the most positive light. 
The time of the school year brought Jackie and her then boyfriend together to discuss the implications of the plans they had for higher education. During this turning point, Jackie and her ex came together to a mutual agreement that going to different colleges meant that they would soon be living in different geographical locations. Even though they decided this meant that they needed to break-up, this decision would not be a negative turning point since their past together was positive and they needed to be happy for each other instead.

In Ingrid's case, her relationship with her ex-boyfriend made more sense to her after he moved and then they began to communicate more. Ingrid said:

I mean he like moved away. Um, but like I said, it's still kinda like casual contact, but I don't really think it's really, I don't think there was really, I mean there was a point where we didn't talk like after the whole thing, but then after we kind of like got, you know, like had the conversation, then it was just kind of like casual after that, if that made sense. Since her recent ex moved away, Ingrid describes the post-dissolution communication as casual or a neutral turning point. She continued to speak about their relationship:

It's like indirectly stay in contact 'cause we have like a group chat that we send stuff in that he's in. But you know what I'm saying, like it's just talking to like a group. So, it's not really like directly to him, but I dunno. It's very, I would say casual in that regard.

Ingrid emphasized the casual interaction with her and her ex-boyfriend. Even after they broke up, they remained connected through shared social connections. The so-called casual, indirect interactions are how they were able to go from an intimate relationship to a platonic friendship.

David elaborated about a turning point that lead to solidifying a platonic relationship with his ex-girlfriend: 
I was teaching English abroad. She had just graduated, and so she had just started a new job, and she had met, well, the person that she's married to now who actually—who works at the same company that she works at. And for me, you know, I was trying to get into dating, and I found someone. So, it was just like, it was during that break. It's like we both did some reflecting, and we both kinda like found someone during that time.

David and his ex-girlfriend took advantage of having time apart after breaking up. David goes on the explain that he would receive updates about his ex's life during that time, and it was a positive turning point. There was not pressure for them to remain close or maintain an intimate relationship anymore. He was relieved to be able to do this with his ex-girlfriend because it showed that, even though their relationship status is different, they can continue to be in each other's lives. David said, “We've been friends for a while now. We talk and text whenever we get the chance to." Despite their differences, David and his girlfriend formed a friendship during their unique circumstances that continues today.

Don referred to how his moving away during a break-up from his then-girlfriend contributed to gradually changing in their relationship into the platonic friendship that it is today. I actually had moved. I was being transferred. So, we did continue to see each other for a bit, and that's where we started to have an on-and-off period. But she actually, prior to us being together, she was dating someone, and she ended up going back to that to that guy at that time. So yeah, after we broke up and stuff, she ended up going back with him. But, the move was a little bit something significant, I would say, I guess.

The communication did not abruptly end when Don and his ex-girlfriend experienced breaking up during a time when he was moving. They created their own terms for their interactions by engaging in an off-and-on intimate relationship. Don refers to the turning point during this time 
as positive. Currently, Don and his ex-girlfriend continue to live away from each other but still continue to manage to keep in contact. Don makes this point clear when he says, "I'll always care about her, and she'll always care about me." Don discovered his ex was a true friend during this turning point.

Like some of the other participants, Megan had to make a decision about the future of her relationship with her then boyfriend when they were not going to live and work near each other anymore. This turning point in their relationship was significant because they had become close after meeting and living in a new city together during a gap year after high school. However, when it came time to move out of their shared city and place of work, Megan knew their relationship was about to change forever. She declared, "The main issue that we sort of had to deal that we aren't going to live in California forever. So, do we really want to make this work sort of long distance or is it not necessarily worth that?" This became a pivotal point in Megan's life, because she experienced a lot of personal growth and comfort in her current relationship with her then boyfriend. She knew she never planned to live in that area forever, and that is why she went through with breaking up with her boyfriend, but decided she wanted to remain friends with him.

Ivy found themselves back together with their boyfriend for a second time, after initially breaking up and getting back together. They anticipated this turning point to be a negative when they told their former boyfriend that they wanted to break-up for a second time. To Ivy's surprise, this break-up was on amicable terms when their boyfriend came to them one day to share important news. Ivy said:

And then the second time we broke up was a couple of years later, and I again started having those same feelings that I did back in freshman year of high school. He was 
starting to hang out with the wrong people, and like he was smoking all the time, and I'm not really into that. So, I was just like, I can't do this again. And then the day before I was going to tell him that I couldn't do it, He told me he was moving.

Ivy looks back at this turning point and remembers it as a positive one:

After he moved to California, I just kind of like just took some time to myself to realize that I wasn't treated correctly, and I did meet my current boyfriend after he had left. But after the break-up we had enough time and space to be a part to where now, like I would say we're on the best terms that I think we've ever been at.

They anticipated breaking up with their then-boyfriend to be a negative turning point, as it turns out they needed distance to be able to maintain a friendship.

Distance created an opportunity for Kylie, Jackie, Ingrid, David, Don, Megan, and Ivy to successfully transition from a romantic relationship to breaking up and maintaining a relationship with someone that they previously dated. Whether they anticipated experiencing turning points that meant they were to separate from someone they were dating at the time or not, they continued to have their exes in their lives somehow. It turns out in these cases, distance makes the heart fonder.

\section{Redefining Boundaries}

Nearly every participant described how their post-dissolution relationship changed the basis of the interactions and relationship as a whole between the participant and their ex. Taken together, these descriptions of change comprise the theme of redefining boundaries. A commonality in participants' talk about redefining boundaries was the purpose of intending to establish new boundaries to some degree in the now-platonic relationship. Whether the participant entered the new stage of their relationship with their ex after an explicit conversation 
about establishing different boundaries or managed them throughout the break-up process, there was always a shift in how the participants communicated with now-platonic friends. Participants freely spoke of their ongoing relationships with their exes and did not limit their responses to TPs about this experience. Redefining boundaries is a theme that consists of some turning points and includes analysis of what participants experienced when they interacted with their exes. Jan spoke about a significant, but surprising moment that occurred post-break-up between them and their ex, after not speaking for four or five months:

'Cause we started hanging out again, we were close, and I started dating somebody else, and he would hang out with us. And he would like, give me advice, which is really cool, because it was completely fine. I think there was maybe one conversation about like, "Is this OK? Like, you don't have to listen to me talk about what's going on with me and this girl.” He's like, “No, that's fine, like I would tell you if I was uncomfortable with it, we're good friends."

Jan viewed this as a positive interaction, because they did not expect their ex to accept them dating someone new or for them to be comfortable with speaking about and giving advice on topics like new romantic partners. Jan's recollection of this turning point describes how two exes achieve this level of closeness and comfort due to time passing post-break-up and addressing each other's limits in a new, platonic relationship.

Other participants spent time with their exes due to having mutual friends. Jackie said, "We hung out and like went to a concert together, but other friends were there, too." Jackie described this as a neutral turning point with her ex because it was a situation wherein she felt inclined to keep a friend group together, even if it placed her in an initially weird social context. However, this one interaction bridged the gap of post-dissolution communication between 
Jackie and her ex, allowing them to eventually come to the decision to remain friends despite their break-up. Jackie said that "the mutual agreement just shows that like we're both mature and you can just end things on a positive note." A social gathering also unintentionally brought Kylie and her ex together as friends, an opportunity for her and her ex to discuss the their newly forming relationship. "I saw him on New Year's Eve, and that's what we were talking about, we were saying that we work better as friends than we did when we were together," agreed Kylie. Another participant, Ingrid, spoke of how she redefined boundaries with her exboyfriend. When Ingrid and her then-boyfriend broke up, she realized she had to be the bigger person by being honest about the direction a break-up would take the relationship. Ingrid decided that since she goes to the same university and belongs to same, small social circle as her ex, that she wanted to be platonic friends with her ex right away. Ingrid said that she told her ex from the beginning of their break-up:

I was like, “Listen, like we're obviously going to see each other. We don't have to be like best friends, but like obviously we're going to have to be like friendly sort of. In this group, like we can't be... I don't know there can't be like tension between us all the time." I was just like, you know, I acknowledge how we felt, all this other stuff, but I was like moving forward like we have to be civil with each other.

When Ingrid explained how this turning point felt to her, she detailed circumstances similar to Jan's and Jackie's. Ingrid provided context to her situation from her and her ex's perspective. Ingrid explained:

I mean, I think in his eyes it was negative, but in my eyes it just like, I would like, it would be worse if I like strung him along. I didn't really like just like say my peace about 
it. Um, that would be kind of unfair to him as well as being unfair to myself because then I would just kind of be like lying, you know?

With the focus being on Ingrid's perspective of this turning point, she preferred to go through with breaking up with her former intimate partner, even if it did subject her to an uncomfortable experience. Their intimate relationship did not end on amicable terms, making the transition to a platonic relationship uneasy, but the explicit conversation that Ingrid made a point of having made her intentions clear and laid down a foundation for future post-dissolution communication.

The situation for David was different, because when he and his ex-girlfriend broke up, they navigated newfound boundaries together. David remarked that he experienced major turning points in his relationship with his ex a few years after breaking up. In those few years, David and his ex considered getting back together, but they ultimately decided to be in each other's lives for a different purpose. David mentioned:

We talked off and on about getting back together sometimes. But then, you know, every time we would talk about it, like I said, it was like we both came to the conclusion that it's like, "Well, I don't want to date you just to date someone. I don't want to be with you just for the sake of being in a relationship, and I like you, but I don't like you in that way." And I think both of us, I think there was a moment where like she thought about getting back together and then a couple of months would pass and then I wanted to get back together. I would say a significant event that happened was about four years after we broke up. We kind of fought about it, and it was a kind of a bad fight. And then we went two and a half months without saying anything to each other after that. And what I mean by that is like two and a half months of no communication whatsoever. Like no 
Facebook messages, no texts, nothing. Then, we started realizing that it's like, you know, we are each other's closest friend, and we didn't want to fight over this.

David stated at the time of the interview, "We've been friends now for almost ten years." David categorized the argument that ended all communication with his ex-girlfriend for a few months as a negative turning point that lead to the positive experience of them realizing that they were meant to be just friends that are close.

Lisa and her ex established long-term boundaries while they were romantically involved but managed to keep their promises to each other after breaking up. She said, "We became blood siblings, you know, the whole unhygienic cutting open the hand." This experience was a huge turning point that remained positive because of the commitment Lisa and her former romantic partner made to each other and fulfilled. Further, Lisa said, "And that was part of what the, you know, blood pact we did way back in the day was meant to symbolize like whether not we're romantic, we will always be friends, and we're family now." This turning point in Lisa's interview is unique because none of the other participants stated that they and their exes decided to define the post-dissolution boundaries before breaking up. Rather, other participants described boundaries as shifting throughout or after the break-up process.

Ava was fine with ceasing all communication with her ex-boyfriend after breaking up. She considered the turning point to be positive, because she had time to recover after separating from her first love. However, her ex reached out to her to attempt to establish post-dissolution communication boundaries. Ava said:

He reached out to me like the week before school started in August. And he basically apologized for everything when we were together. I told him, "I think we can move past it, I forgive you, and I wish all the best for you." And he said, "I hope we can try and be 
friends because I know that we ended up on bad terms last time.” And I was hesitant about it at first.

Even though Ava described feeling hesitant at first, she decided to go through with being friends with her ex. Ava explained how this experience was positive, even though navigating it was a new experience for her:

I was really surprised. I was expecting to not hear from him ever again, but I figured it must've been really hard for him to reach out to me in the first place to apologize. So, I decided, you know, it happened a long time ago. We both probably learned from it and grew up from it. So why not try and be friends? We'll see if it works.

Ava decided that she wanted to be friends with her ex, but the process has not been all positive. Ava and her ex continue to test the boundaries of a platonic friendship, giving her experience ups and downs. Despite the difficulties, Ava indicated she is happy to have someone in her life that she considers herself to be close with:

I'd say, we're good friends. We just have to work on boundaries, cause occasionally he'll start flirting and then I would do the same, and I say wait friends don't do that or we shouldn't do that. But yeah, I consider him a close friend of mine.

Eddy experienced a turning point like Ava. During his interview, Eddy shared how he and his ex-girlfriend began speaking again after a two-year hiatus of no post-dissolution communication. Like Ava, Eddy did not expect to hear from his ex since breaking up, and she surprised him, too. When his ex-girlfriend reached out to him, she was clear about how she wanted their relationship to change, despite their past as a couple. Eddy recalled: 
I mean it was, it was pretty straightforward at the beginning. We just said that we wanted to be friends, and we were both okay with that. So yeah, it was nipped in the bud pretty early that we would just be friends.

Eddy believes this turning point was positive since he shares mutual friends with his exgirlfriend. His post-dissolution communication with his ex removes any tension between them and their mutual friends.

Not every participant experienced ground-breaking turning points that transformed their relationships into platonic ones. Luke described a more neutral situation where he and his exgirlfriend decided to be friends, but approached the situation in a humorous, but casual way: I think we've joked about it before but nothing serious. Like we have not actually had like a conversation of like sitting down and talking about the transition. Like, we just kind of mutually set boundaries and just went from there. But we didn't really have that talk.

Throughout his interview, Luke goes into the casual nature of the relationship he has with his ex now. Overall, Luke views his relationship with his ex-girlfriend as something more meaningful because the relationships means a lot to him, despite the neutral turning points.

It does mean a lot, and it just means more because, to me, we kind of overcame something that a lot of people don't, is to be friendly after a break-up. Which, really, you always say you're going to be friends, but you never actually are. So, to me it means a lot because it's not like we didn't enjoy each other's company or didn't enjoy talking to each other. We just knew we couldn't be in an intimate relationship. It just didn't work out. Mark also explained what he and his former girlfriend overcame to achieve while they became platonic friends. In his situation, he and his ex-girlfriend met because of mutual friends. Mark gave his ex space after breaking up, which meant excluding himself from social activities, 
knowing his ex would join their friends. Mark explained, "It just felt awkward at the time and like everything just kind of felt weird." Even though Mark described this initial setback as a negative turning point, it allowed his relationship with his ex to recover and lead to talking about setting new boundaries in place. Mark said:

We talked to each other and at the time it was almost me, more so, liking her more than she was liking me. She saw me more as a friend where I was starting to like her again. And so, like, that's where she pretty much told me like, hey, we know where this is going to end up and I don't want to. I don't want you to get your feelings hurt. I don't want my feelings hurt.

After that conversation, Mark and his ex-girlfriend were able to be on friendly terms, enjoy interacting with each other, and moved past their differences. This theme encompasses the ways post-dissolution interaction changes the present boundaries in an ongoing post-dissolution relationship. At times, the participants chose to test the boundaries of their relationship with their exes. Other times, participants made it a point to have an explicit conversation about what the new boundaries are with their now former significant other. These turning points reveal that the transition into a platonic relationship with an ex is not easy or done without mistakes. Nonetheless, redefined boundaries are something individuals experience when they achieve going from an intimate relationship to a positive, platonic friendship. Also, it is important to emphasize that this theme is unique because it consists of responses from participants that link to more than one specific occurrence or turning point. For some participants, turning points accumulated over time through ongoing interactions with their ex. In redefining boundaries, some relationships changed right away, after breaking up, and others managed to become friendships slowly, over time. 


\section{Providing Ongoing Support}

In the providing ongoing support theme, participants described when they willingly continued to give or receive post-dissolution support to/from their former significant other. These instances of post-dissolution support provided insight into the purpose and process of communicating post-dissolution support. Like redefining boundaries, this theme consists of responses that reflect on what occurred during a friendship the participant had with an ex, because participants were not limited to answering with turning points.

When David and his ex-girlfriend communicate, it is on a mutual basis. He never denies speaking with his ex, and he is happy when they do have time to interact. David said:

I think it's like we just naturally have that desire to communicate with each other because really, even now, I consider it a mutual reaching out. Like, she reaches out to me about random things, and I'll reach out to her about random things. It's not like one of us is doing it more than the other, if that makes sense.

David emphasizes the importance of balance during post-dissolution communication. He maintains boundaries with his ex, making sure to be considerate of how often he reaches out to his ex. This could be why David believes every post-dissolutional turning point was positive. David's case is an example of how moderation is key for post-dissolution communication.

Jan brought up how they felt when they learned that their ex-boyfriend was in a new romantic relationship in their interview. When asked about positive turning points, Jan responded, "I think with Lucas, it was him getting into his new relationship with Pam. Because that was kind of closure, I think for both of us." Today, Jan is very open about how much they support the seriousness of their ex and their new romantic partner's relationship. Jan said, "I'm still waiting for my wedding invitation to Lucas and Pam's wedding. I'm serious, I told Pam, I 
was like, 'I wanna be in the fucking bridal party."' Jan's statement exemplifies how close they consider themselves to be with their ex and their ex's new partner.

It is important for Jan to make their perspective on post-dissolution communication clear for others to understand. In their interview, they stated:

I like to tell people that, with Pam and Lucas, that I'm their number-one fan. So that people understand that, when I say I truly am very good friends with my exes, like, that's how good of friends I am with them, is that I love who they are with.

Jan expressed the joy they feel for their ex and their new relationships. They are among other participants that shared about the support they give to their former partners.

Jackie, among other participants, did not want to end communicating with her ex. For her, this meant that she tried to see the break-up from her ex-boyfriend's perspective. When Jackie refers to when her ex began communicating with her after their break-up, she said:

It was also like he didn't really hang out with anyone much other than our friend group. And like everyone in the friend group doesn't see like the sensitive side, that stereotypical thing, like, “Oh, boys can’t be sensitive” type thing. So, it's just like I was someone easy to talk to 'cause, like, I got it and he knew I would be like, "No judgment, whatever." Jackie found a way to be socially supportive of her ex-boyfriend when both of them knew that they were on post-dissolutional communicative terms. Now, Jackie and her ex feel like they have a unique way to interact that they do not share with their other friends.

Kylie and her ex-boyfriend take advantage of catching up whenever they encounter each other. Kylie talked about instances when she feels close to her ex and stated:

I saw him at a party. And I was talking to him for a while, and then he texted me like last week. We were just talking because his sister just got engaged, and I liked her a lot, and 
he was just telling me about their wedding. So, I was happy for her, it's very normal, I guess.

Kylie felt her interactions with her ex have purpose because they consist of important life updates. When Kylie sees her ex in person, it is a positive turning point for her. Their conversations discuss the subject of post-dissolution communication. "I think when both of us like moved on, I think that we were just both fine with being friends, and he's happy for me at least." Kylie expressed the relief that she experienced from a post-dissolution relationship that continues to be platonic.

Due to having a mutual friend group, Ingrid and her ex hung out after breaking up. Ingrid found herself regularly around her ex and wanted to be supportive of his decisions, but it was apparent that was not enough. Ingrid entered a new platonic relationship anticipating positive turning points to come. Soon, Ingrid and their friends become concerned over her ex's behavior. Ingrid explained:

I mean, I didn't have a problem with him like talking to other girls, if that made sense. But just the way he was doing it, it was like, I kind of was noticing like, he's like doing that to get like my attention. Just how he was like handling himself, and, like, what he was saying and stuff. And then I kind of didn't really like, I mean I acknowledged it to myself, but I didn't really say to other people 'cause I'm not going to be the person that's like, "Oh he's doing that for my attention," you know, just kind of being like full of myself in that regard. But then when people started like saying it to me like, "Oh, it's like really obvious that that's what's going on." I was just kinda like, okay, I did realize that. And then when I realized that it was kind of, you know, kind of like spiraling down is 
when I went ahead and was like, listen, we got to talk. And then after that talk it was definitely better after that.

After debating, Ingrid came to the conclusion that she must express to her ex that she was concerned about him. Even though she was not forced to address her concerns, she described a situation where she was obligated to take action. Ingrid went out of her way to intervene in the situations her ex was in. Ingrid managed to get through this negative turning point by looking after her ex. For Ingrid, post-dissolution communication involves caring about the well-being of one's ex.

Don found himself in a similar situation after he suddenly resumed speaking with his ex, he grew concerned for her. Don discussed, "I guess we had stopped talking for a while and, we kinda had parted our ways, but there was, she had a significant issue go on, that because of that, it kind of brought us back together as friends." This is an example of a turning point where someone wanted to give their ex a form of support after breaking up and to be in a new, platonic friendship with them.

Don said he wanted to be there to emotionally support his ex once he learned of what she was going through. Don's caring nature contributed to post-dissolution communication. Ava also continues to support her ex through difficult times. Ava described how her ex relies on her:

We were each other's first love, so I guess it's hard to let go of that. And I feel like he can talk to me about anything 'cause he's got a lot of, he's got a lot of stress going on back at home. So, I think it's nice. Like I tell him what's going on or like I can keep it confidential, I think. 
Ava and her ex continued to trust each other after their break-up. After experiencing this turning point, Ava felt positive about the interactions her and her ex have. When asked about how she feels about her post-dissolutional relationship, Ava replied:

I think it's important to me because he was an important part of my life at some point. He taught me a lot about what I want in a relationship. He was my first love, so I think it's, it's hard to let him go like that. So, I think it means a lot that he's still in my life. Even with Ava new to post-dissolution communication, she feels as though she can mutually reach out to her ex, should she need something. Mark had a similar relationship with his ex-girlfriend. Mark elaborated why it is convenient for him to have support from his current platonic relationship:

And so like, it's nice because I still have a friend, and if I ever need anything, like she's there. Like, actually, the other day, she emailed me an internship kind of thing that like I was looking into and she's like, “Hey, if this helps, like I don't know what you're going to do for the summer, but here's this." And so, like we always try and help each other out kind of thing.

For Mark, this whole experience is due to positive turning points that led to a friendship with his ex. He mentioned that he does not have any negative feelings towards his ex. When reflecting on his experience going from a romantic relationship to a platonic one, Mark said: I don't think I really have any negative experience with it to be honest. I think it's more so just, it was just nice to have someone for a little bit and to see that this isn't what I wanted. It was nice to be able to experience something. And not ruin a friendship, I feel like, especially 'cause we were friends before we started like talking. 
Ivy is like the other participants and supports their ex, but only from a distance. Ivy made that evidently clear when they stated:

He tends to like get in and out of relationships really quickly. So, he'll tell me a lot about those relationships, and it's always kind of like, it's hard to keep up with like every single person that he's involved with.

Ivy is happy to be there for their ex, to listen and make him feel supported. However, Ivy feels neutral about this turning point. Ivy said:

Um, it doesn't, I really don't have any sort of feelings towards it because we are like, one we're apart enough to where it does not affect me. And then the other part of it is, I know that he's trying to find someone, but it is very, like, it's always kind of not the same story, but it's always kind of the same types of people.

Ivy is there for their ex-boyfriend, but in their own, different way compared to the other participants. They do not overstep the boundaries that are in place by getting overly involved. They prefer not to express much concern or intervene with their ex's choices and actions.

Lisa sums up why she is so comfortable with comforting her ex. For her, it was a rite of passage to transition into a platonic friendship while continuing to be supportive of her ex. Since she already knows important details about her ex, their post-dissolution relationship did not change their communication style. Lisa explained:

And then also like, just in terms of how that defines our relationship, like I think anytime you're in those circumstances with someone where you, you are the only two that have intimate knowledge of a specific piece of information or, or set of information, there's going to be some kind of like bond, right? Okay. 
Lisa also mentioned that, no matter what turning points occurred, she would continue to be supportive for her ex-boyfriend's sake. She makes it clear that she would continue to be there for her ex no matter what. Lisa declared that no matter what occurred in the past or what will occur moving forward, her relationship with her ex is "positive or negative, but there's something tying you two together forever." Lisa and her ex are now married to different people but continue to have a post-dissolution relationship with each other.

\section{Conclusion}

It is evident from the 13 participants that it is possible for them to have a platonic relationship with someone they previously dated. In particular, three types of turning points assist in constructing the post-dating, platonic relationship: redefining boundaries, framing distance as reparative, and providing ongoing support. Most of the turning points described by participants were positive, but that does not mean that the analysis excluded experiences with negative turning points. Indeed, the results show fluctuation among and within post-dissolutional relationships. In the following, and final, chapter, I review the three themes and provide implications for future research regarding post-dissolutional communication. 


\section{CHAPTER V: DISCUSSION}

The aim of this qualitative analysis was to describe the turning points that individuals experience while in a platonic relationship with an ex-partner. The analysis concluded that the participants indicated three major themes that described their experience that I call framing distance as reparative, redefining boundaries, and providing ongoing support. The following discussion is organized around the implications of the results and directions for future research.

\section{Implications of the Results}

Overall the three themes, framing distance as reparative, redefining boundaries, and providing ongoing support, begin to explain what post-dissolution communication interactions entail. The themes reflect how much individuals' relationships fluctuate, being casual, distant friends with an ex. In all, the results from the participants shed light on the positive aspects of post-dissolution communication and allows their situations to be examples that influence interpersonal communication studies moving forward.

The purpose of this study is to understand the significance of post-dissolution communication by capturing first-hand accounts from individuals that are friends with an ex. The findings extend literature on post-dissolution communication. Many previous studies do not focus on communication patterns beyond relationship dissolution (Busboom, Collins, Givertz, \& Levin, 2002), or in rare occasions when researchers studied post-dissolution communication, the samples consisted of divorced couples (Hogerbrugge, Komter, \& Scheepers, 2012; Koenig Kellas, 2006). This study sought answers to what pre-marital individuals experienced while they became friends with an ex and what the impact of that experience was. I am confident that this study's purpose is fulfilled, and speaks of the unique interactions the participants encountered while sustaining a friendship with an ex. 
Perhaps most importantly, something the participants have in common is that they have gone through various relationship patterns and stages. Thus, their experiences validate and challenges existing research. Knapp and Vangelisti (1992) created the staircase model that describes the ways intimate relationships form and then deteriorate, outlining each process in five steps. When forming an intimate relationship, individuals experience initiating, experimenting, intensifying, integrating, and bonding. I argue that individuals can experience these same steps while forming a friendship with an ex. I spoke with 13 individuals that successfully became friends with a former intimate partner. Their situations mean that they initiated or agreed to initiate a friendship with an ex, like the first step of the staircase model. In a new friendship, individuals experiment with the terms of the relationship, whether that be figuring out boundaries or acceptable topics to discuss, like in the staircase model's second step, experimenting. The fourth stage of forming intimate relationships, integrating, is similar to how participants acclimated to the new ways their ex is in their lives, for example, negotiating how to continue hanging out with a mutual friend group that they share with an ex. During the final stage, bonding, individuals became comfortable and happy in their new friendships, like many participants said to be true throughout the interview portion of this study.

While all the participants distanced themselves from an intimate relationship with their exes, the results show that they did not follow through with each of Knapp and Vangelisti's (1992) staircase model steps. Since every participant continued to have a friendship with their ex, it is arguable whether they faced the stagnating, avoiding, or terminating stages during their former intimate relationships. At stagnating stage, couples have shorter conversations or avoid interacting with each other because they're not getting along while they are beginning to breakup. However, participants recalled turning points where breaking up opened communication 
lines and invitations for support between the individuals and their exes in each of this study's three themes, redefining boundaries, framing distance as reparative, and providing ongoing support. When couples avoid each other and distance themselves from the intimate relationship, they are in the avoiding stage. This was not true for participants that held explicit conversations with their exes to redefine their relationships, continued to socially or emotionally support their exes through stressors and the relationship transition. Perhaps, the avoiding stage was true in situations where individuals or their exes moved away because of the physical distancing. Last, the termination stage predicts that exes will not continue to have each other in their lives. I argue that this stage does not apply to people who continue or return to have some form of relationship with their ex, especially friendships. No matter what turning points the participants experienced, they all have their exes in their lives in their own ways.

Duck's (1982) four-stage approach to relationship dissolution provides a better theoretical framework to describe the phenomenon of transitioning from intimate partners to friends. Based on the results of the present study, I analyze how Duck's (1982) four stages of relationship dissolution compares to what the participants described when they became friends with an ex. Participants made references to the intrapsychic stage, where they were unhappy in their intimate relationship with their ex and assessed continuing a friendship as an option as a result of proceeding with a break-up. During the dyadic phase, someone in the relationship discussed breaking up with the other person and the possibility of becoming friends after. People announce their break-up in the social phase. This may be where individuals that continue to be friends with their exes include communication about their new friendship, but I assume this based on my findings. The grave-dressing stage is when people process their break-ups, and in terms of post-dissolution communication, make sense of their new friendships. Rollie and Duck 
(2006) added a fifth stage that includes a period where individuals learn from their previous intimate relationship. I believe this is the opportunity where participants learned how to be in a friendship with an ex and what that new relationship will consist of, which includes deciding how they are going to communicate with them moving forward.

Participants discussed the various turning points and social exchanges they endured while becoming friends with their exes. Turning points allow researchers to analyze and determine the meaning of communication while providing a basis to understand the changes and patterns in a relationship further (Baxter \& Pittman, 2001). Since the participants are friends with their exes now, the turning points they recall and the interactions with their exes put the implications of break-ups into question. In previous research, VanderDrift, Wilson, and Agnew (2012) state that relationship dissolution leads to negative outcomes, but I do not think this statement applies to some people who continue to be friends with their ex. The participants reflected on their experiences following the break-up with their exes, and many described turning points where they felt inclined to terminate intimacy or they were happy to accept that their relationships were about to end. In these situations, the participants indicated that they were relieved to become friends with their exes or felt like it was a good decision for their relationships. Even some participants who were not friends with their exes soon after the breaking up eventually became friends. The participants mention that important turning points challenge what is known about the effects of break-ups.

Participants were asked to recall the turning points that occurred throughout their relationships with their exes, but some considered a series of interactions transformed their platonic friendships. Some participants established a friendly relationship with their ex after ongoing conversations that occurred over time, as opposed to this happening due to a single 
turning point. In this study, participants described the ways their relationships changed, but their responses not fulfill the traditional definition for TPs. Thus, these findings may extend the understanding of what turning points can be in research.

Some of the participants chose to disclose what Altman and Taylor (1973) classified as "superficial" information with their ex, but that was not true in all cases. In the themes, redefining boundaries, framing distance as reparative, and providing ongoing support, some participants continued to speak of personal and sensitive topics with their ex. Some felt as though they should not limit what to speak with their ex about, no matter the context. Many participants did not feel like they needed to change the nature of their communication with their exes. Even though they were "just friends" with their ex now, they felt like they were close with that person. There were reports of post-dissolution communication benefitting some individuals whether they acquired or sought social and emotional support from their exes. Social exchange theory (Homans, 1958; Thibaut \& Kelley, 1959) predicts that people deem relationships sustainable when the interactions bring more rewards than costs. Perhaps, participants continued to be friends with their exes because they experienced positive relational elements. In all of the themes, participants directly spoke of the satisfaction they experience in their platonic relationships with their exes. All participants indicated that they were pleased to be in a nowplatonic relationship. Thus, this implication suggests that further investigation of post-dissolution communication should explore communication patterns of healthy communication styles that benefit people's well-being, including the communicative value of emotional and social support.

The results are not the first of their kind, because there is existing research about postdissolution communication. The results section adds to previous findings that there are valid reasons as to why people continue to have a friendship with an ex (Koenig Kellas, 2006; Koenig 
Kellas et el., 2008; Schneider \& Kenny, 2000); however, more research is needed on postdissolution communication and turning points. The results from the study are unique because participants spoke about their personal experiences during in-depth interviews. The three themes go beyond reasons to be friends with an ex because they want to get back together (Kaplan \& Keys, 1997; Schneider \& Kenny, 2000) or felt obligated to maintain a post-dissolution relationship out of necessity or convenience (Foley \& Fraser, 1998). Participants generated results that encompass themes where friendships with exes are comfortable, full of support, and forgiving despite the periods of trial and error. In sum, the three themes derived from participants' responses begin to formulate ideas about post-dissolution communication that extend the trajectories of relationship patterns and stages using turning points and the lens of SET. These findings contribute to an important subject, since little is known about former romantic partners who continue to communicate after breaking up (Koenig Kellas, 2006; Schneider \& Kenny, 2000). The work begins to scratch the surface, and there is a plethora of information available to continue studying the interactions between individuals and their exes.

The findings reveal that every participant experienced unique circumstances consisting of very intimate relationships that resulted in platonic friendships. The theme "redefining boundaries" includes the changes in the relationships where the termination of an intimate relationship meant there were limits in the following platonic friendship. Or the contrary, participants related to their ex more so after becoming friends, because they did not need to worry about the intimate aspects of the relationship anymore. In the theme, framing distance as reparative, participants overcame the circumstances that changed the direction of their intimate relationships. Participants become immediately supportive when they discovered their ex needed support or realized their ex continued to be support systems for them in the theme, "still 
supportive." No matter how harshly or abruptly their intimate relationships terminated. For the most part, the turning points and interactions that make up the three themes were positive. The participants considered some of their experiences to be negative, but most were positive turning points and experiences. This suggests that post-dissolution communication is more alike messages and resources from other types of relationships.

The results suggest that there are benefits to post-dissolution communication because of the positive turning points that the participants reported. I began to explore the implications of turning points and the theoretical framework of SET when the participants had attained a friendship with an ex through this study. The findings reveal that it is possible for intimate partners to become platonic friends, despite negative setbacks like a turbulent break-up. However, a lack of research on this subject makes it difficult to fully understand other aspects of post-dissolution communication. There continues to be much to discover about post-dissolution communication when it comes to individuals that are friends with an ex.

\section{Directions for Future Research}

\section{Strengths and Limitations}

A strength of the study is that I reached saturation after 13 interviews, although the criteria to participate was specific. Even though my sample consisted of individuals from only one large Midwestern university, I had the privilege of interviewing participants with a range of difference, based on their demographics and experiences. The participants' ages ranged from 1948 and length of time in intimate and platonic relationships, in which provides maximum variation that strengthens this study's results, according to Lincoln and Guba (1985). Thus, demographics in terms of age and the various lengths of time in relationships meet important criteria for credible results (Lincoln \& Guba, 1985). The participants' different ages reflect 
voices from both traditional and non-traditional college students. The semi-structured interview method was another aspect that allowed participants to go into detailed accounts of their experiences with post-dissolution communication. The interview protocol created an inviting environment that allowed participants to go into as much or little detail discussing their relationship with their exes. Also, the theoretical framework strengthened the study to value communicative transitions by intertwining turning point analysis with social exchange theory. These strengths allowed me to have a comprehensive understanding of my participant's experiences which reflects throughout the study.

Aside from the strengths, there are also limitations to my study. The lack of variation in participants' demographics in terms of race or ethnicity hinders the sample from achieving other credibility criteria. Eleven of the 13 participants were Caucasian, and there are benefits to having a more diverse sample. Diversity includes perspectives from different cultures, which generates richer results with a variety of ideas and action about post-dissolution communication. Even though I believe it is important to hear from students at universities, individuals outside of the university also have valuable experiences to share that require other recruiting methods. Another limitation I placed on this study was narrowing my results to people with on-going relationships with exes, this generated more positive responses for further analysis. It would be interesting for researchers to include participants that have a negative relationship or non-existent relationship with an ex. Future research should use sampling techniques beyond convenience and snowball sampling and called for wider range of participants.

\section{Future Research}

I conducted this research because there is a gap in research exploring post-dissolution communication among pre-marital couples. Although I am not the first to conduct research about 
post-dissolution communication, there was not an abundance about this regard and turning points. However, any study about post-dissolution communication would reflect individual's experiences about a subject that are not widely heard of in research. In future research, it is worth examining the ways exes communicate via computer-mediated communication, for example, via social media. Due to a small amount of research conducted after the point of dissolution, it would be beneficial for future research to focus on this while generating updated models and theories about unique interactions between exes. Such research seeks to understand the communication pattern better of post-dissolutional interactions.

\section{Summary}

This study included qualitative methods to understand the turning points individuals experience with post-dissolution communication. The study gave the participants an opportunity to share their experiences about their platonic friendships with exes. The conclusion of the generated results calls for more research to be done on this subject in interpersonal communication studies, because there is more to discover about the communication patterns and stages when people transition from an intimate relationship to a platonic one.

I conducted this study without knowing what to expect, because, personally, I never maintained a friendship with any of my exes. I was interested in this topic because I wanted to investigate others' experiences that were different than my own. All 13 of the participants' responses revealed the subjective matter of post-dissolution communication. No matter what turning points the individual participants experienced, every one of them value and maintain the relationship they have with their exes. Post-dissolution relationships benefitted each of the participants because they did not lose contact with someone due to a break-up, and the circumstances allowed them to keep an ex in their lives. I make the call for future research to 
generate further results that spread awareness about this topic. I hope future interpersonal communication research continues to share post-dissolutional communication experiences moving forward. 


\section{REFERENCES}

Altman, I., \& Taylor, D. A. (1973). Social penetration: The development of interpersonal relationships. New York, NY: Holt, Rinehart \& Winston.

Baumeister, R. F., \& Leary, M. R. (1995). The need to belong: Desire for interpersonal attachments as a fundamental human motivation. Psychological Bulletin, 117, 497-529. doi:10. 1037/0033-2909.117.3.497

Baxter, L. (1984). Trajectories of relationship disengagement. Journal of Social and Personal Relationships, 1(1), 29-48. doi:10.1177/0265407584011003

Baxter, L. A., Braithwaite, D. O., \& Nicholson, J. H. (1999). Turning points in the development of blended families. Journal of Social and Personal Relationships, 16, 291-313. doi:10.1177/0265407599163002

Baxter, L. A., \& Bullis, C. (1986). Turning points in the development of blended family relationships. Journal of Social and Personal Relationships, 16, 291-313. doi:10.1177/0265407506064210

Baxter, L. A., \& Pittman, G. (2001). Communicatively remembering turning points of relational development in heterosexual romantic relationships. Communication Reports, 14(1), 117. doi:10.1080/08934210109367732

Braun, V., \& Clarke, V. (2006). Using thematic analysis in psychology. Qualitative Research in Psychology, 3, 77-101. doi:10.1191/1478088706qp063oa

Busboom, A. L., Collins, D. M., Givert, M. D., \& Levin, L. A. (2002). Can we still be friends? Resources and barriers to friendship quality after romantic relationship dissolution. Personal Relationships, 9, 215-223. doi:10.1111/1475-6811.00014 
Dailey, R. M., LeFebvre, L., Crook, B., \& Brody, N. (2016). Relational uncertainty and communication in on-again/off-again romantic relationships: Assessing changes and pattern across recalled turning point. Western Journal of Communication, 80(3), 239-263. doi:10.1080/10570314.2015.1094123

Dailey, R. M., Rossetto, K. R., McCracken, A. A., Jin, B., \& Green, E. W. (2012). Negotiating breakups and renewals in on-again/off-again dating relationships: Traversing the transitions. Communication Quarterly, 60(2), 165-189. doi:10.1080/01463373.2012.668847

Duck, S. (1982). A topography of relationship disengagement and dissolution. In S. Duck (Ed.), Personal relationships. 4: Dissolving personal relationships (Vol. 4, pp. 1-30). London, UK: Academic Press.

Ferrara, M. H., \& Levine, T. R. (2009). Can't live with them or can't live without them?: The effects of betrayal on relational outcomes in college dating relationships. Communication Quarterly, 57(2). 187-204. doi:10.1080/01463370902881734

Foley, L. \& Fraser, J. (1998). A research note on post-dating relationships: the social embeddedness of redefining romantic couplings. Sociological Perspectives, 41, 209-219. doi: $10.2307 / 1389360$

Frisby, N., Sidelinger, R. J., \& Booth-Butterfield, M. (2015). No harm, no foul: a social exchange perspective on individual and relational outcomes associated with relational baggage. Western Journal of Communication, 79(5), 555-572.

doi:10.1080/10570314.2015.1075585 
Frost, D. M., Rubin, J. D., \& Darcangelo, N. (2016). Making meaning of significant events in past relationships: Implications for depression among newly single individuals. Journal of Social and Personal Relationships, 33(7), 938-960. doi:10.1177/0265407515612241

Galvin, K. M., \& Wilkinson, C. A. (2006). The communication process: Impersonal and Interpersonal. In K. Galvin \& P. Cooper, Making Connections: Readings in Relational Communication (pp. 281-290). Los Angeles: Roxbury.

Goffman, E. (1952). On cooling the mark out: Some aspects of adaptation to failure. Psychiatry, 15 (4), 451-463. doi:10.1080/00332747.1952.11022896

Hand, L. S., \& Furman, W. (2009). Rewards and costs in adolescent other-sex friendships: Comparisons to same-sex friendships and romantic relationships. Social Development, 18(2), 270-287. doi:10.1111/j.1467-9507.2008.00499.x

Hogerbrugge, M. J. A., Komter, A. E., \& Scheepers, P. (2012). Dissolving long-term romantic relationships: Assessing the role of the social context. Journal of Social and Personal Relationships, 30(3), 320-342. doi:10.1177/0265407512462167

Homans, G. C. (1958). Social behavior as exchange. American Journal of Sociology, 63(6), 597606. doi:10.1086/222355

Johnson, A. J., Wittenberg, E., Haigh, M., Wigley, S., Becker, J., Brown, K. \& Craig, E. (2004). The process of relationships development and deterioration: Turning point in friendships that have terminated. Communication Quarterly, 52(1), 54-67. doi:10.1080/01463370409370178

Kaplan, D. L., \& Keys, C. B. (1997). Sex and relationships variables as predictors of sexual attraction in cross-sex platonic friendships between young heterosexual adults. Journal of Social and Personal Relationships, 14, 191-206. doi:10.1177/0265407597142003 
Knapp, M. L., \& Vangelisti, A. L. (1992). Interpersonal communication and human relationships, Boston: Allyn \& Bacon.

Knapp, M. L., \& Vangelisti, A. L. (2006). Relationship stages: A communication perspective. In K. Galvin \& P. Cooper, Making Connections: Readings in Relational Communication (pp. 132-139). Los Angeles: Roxbury.

Koenig Kellas, J. (2006). “The worst part is, we don’t even talk anymore”: Post-dissolutional communication in break-up stories. In K. Galvin \& P. Cooper, Making Connections: Readings in Relational Communication (pp. 281-290). Los Angeles: Roxbury.

Koenig Kellas, J., Bean, D., Cunningham, C., \& Yun Cheng, K. (2008). The ex-files: Trajectories, turning points, and adjustment in development of post-dissolution relationships. Journal of Social \& Personal Relationships, 25(1), 23-50. doi:10.1177/0265407507086804

Lannutti, P. J., \& Cameron, K. A. (2002). Beyond the break-up: Heterosexual and homosexual post-dissolutional relationships. Communication Quarterly, 50, 153-170. doi:10.1080/01463370209385654

Lincoln, Y.S., \& Guba, E.G. (1985). Naturalistic Inquiry. Newbury Park, CA: Sage Publications. Lindlof, T. R., \& Taylor, B. C. (2011). Qualitative communication research methods (3rd ed.). Thousand Oaks, CA: Sage.

Metts, S., Cupach, W. R., \& Bejlovec, R. A. (1989). "I love you too much to ever start liking you": Redefining romantic relationships. Journal of Social and Personal Relationships, 6, 259-274. doi:10.1177/0265407589063002

Parcell, E. S., \& Maguire, K. C. (2014). Turning point and trajectories in military deployment. Journal of Family Communication, 14, 129-148. doi:10.1080/15267431.2013.864293 
Rollie, S. S., \& Duck, S. (2006). Divorce and dissolution of romantic relationships: Stage models and their limitations. Handbook of Divorce and Relationship Dissolution, 223-240.

Rubin, H. J., \& Rubin, I. (2012). Qualitative interviewing: The art of hearing data. Thousand Oaks, CA: Sage.

Sahlstein Parcell, E. (2013). Trajectories research in family communication: Toward the identification of alternative pathways for inquiry. Journal of Family Communication, 13(3), 167-177. doi: 10.1080/15267431.2013.799027

Schneider, C. S., \& Kenny, D. A. (2000). Cross-sex friend who were once romantic partners: Are they platonic friends now? Journal of Social \& Personal Relationships, 17(3), 451-466. doi: $10.1177 / 0265407500173007$

Stafford, L. (2008). Social exchange theories: Calculating the rewards and costs of personal relationships. In D. Braithwaite \& P. Schrodt (Ed.), Engaging theories in interpersonal communication: Multiple perspectives (pp. 403-414). Thousand Oaks, CA: SAGE Publications, Inc.

Sprecher, S., Felmlee, D., Metts, S., Fehr, B., \& Vanni, D. (1998). Factors associated with distress following the breakup of a close relationship. Journal of Social and Personal Relationships, 15, 791-809. doi:10.1177/0265407598156005

Sprecher, S., Zimmerman, C., \& Fehr, B. (2014). The influence of compassionate love on strategies used to end a relationship. Journal of Social and Personal Relationships, 31(5), 697-705. doi:10.1177/0265407513517958

Thibaut, J. W., \& Kelley, H. H. (1959). The social psychology of groups. New York, NY: Wiley. 
Usera, D. (2018). "Cooling the mark out" in relationship dissolution. Kentucky Journal of Communication, 37(2), 4-22. Retrieved from:

https://www.academia.edu/7780377/_Cooling_the_mark_out_in_relationship_dissolution

VanderDrift, L. E., Wilson, J. E., \& Agnew, C. R. (2012). On the benefits of valuing being

friends for nonmarital romantic partners. Journal of Social and Personal Relationships, 30(1), 115-131. doi: 10.1177/0265407512453009 


\section{APPENDIX A: RESEARCH BOARD RECRUITMENT}

If you are at least 18 years old and have a platonic friendship previous romantic partner, please email Desiree at dhern18@ilstu.edu to schedule your interview. With your permission, I will audio record the interview and then I will delete the recording once I transcribe the interview. I will also change your name on the final thesis. 


\section{APPENDIX B: EMAIL RECRUITMENT}

Dear

I am a graduate student in the School of Communication and am conducting a research study on the significance of platonic friendships between ex-romantic partners for my master's thesis. If you are at least 18 years old and have a platonic friendship previous romantic partner, then I request your participation.

You are invited to participate in an interview study regarding the turning points that took place after a break-up with a former romantic partner. The interview may take place in person. Particularly, this study seeks to understand how former romantic partners maintain a platonic relationship after romance ends. It also aims to understand post-dissolutional communication.

The interview will take approximately 30-60 minutes. It will be confidential (I will not share your identity with others). I will change your name on the final paper for this project. Your participation will be completely voluntary. You may decide not to answer any question, and you can stop the interview at any time. All questions will focus on the significant events that lead to a platonic friendship with a former romantic partner.

Please direct any questions and/or comments to my thesis advisor, John Baldwin (jrbaldw@ilstu.edu), or to me.

If you would like to participate, please contact me at the e-mail address below.

Sincerely,

Desiree Hernandez

Graduate Student, School of Communication

Illinois State University

dhern18@ilstu.edu 


\section{APPENDIX C: INFORMED CONSENT}

\section{Informed Consent Form}

\section{Introduction}

This research study is being conducted by Desiree Hernandez as part of her master's thesis under the direction of John R. Baldwin, in the School of Communication at Illinois State University, to understand the significance of platonic friendships between ex-romantic partners. You must be over 18 years of age to participate.

\section{Procedures}

If you choose to take part in this research study, you will be asked to participate in an openended interview. This interview will take approximately 30 to 60 minutes and will be audiorecorded. There will also be some short demographic questions to describe you, which you can answer at the time of the interview.

\section{Risks/Discomforts}

Risks include possible psychological stress and possible loss of confidentiality and resulting loss of status or reputation. Beyond this, the risks are no more than those experienced in everyday life. To mitigate risks, audio files and transcripts will be de-identified, with no record connecting them to specific participants; all relevant documents - digital and paper-will be kept in locked locations. If you feel discomfort as a part of the interview, you may contact ISU Counseling Services at (309) 438-3655.

\section{Benefits}

Through this study, I hope to understand platonic friendships between ex-romantic partners, as it is a field with limited research. While there are no direct benefits to participants, they could help provide useful information that is important to this area of research.

\section{Confidentiality}

All information will remain confidential and will only be reported as group data with no identifying information. However, when required by law or university policy, identifying information (including your signed consent form) may be seen or copied by authorized individuals. Any names that you mention during the interview, including your own name and the names of others, will be changed to pseudonyms during transcription. If you choose a public location for the interview (e.g., a restaurant), I cannot guarantee that anyone overhearing the conversation will maintain confidentiality. Results will be documented in my master's thesis and submitted to the graduate school for uploading to the Milner Library thesis/dissertations database. After your data have been deidentified, your data may be used in other research projects. Data may be used for poster presentations, conference papers, or possible publications.

\section{Participation}

Your participation in this study is voluntary. You may refuse to answer any question. You may skip or refuse to answer questions if you feel uncomfortable, and if you choose not to participate or to withdraw from the study at any time, there will be no penalty. 


\section{Will you receive anything for participating?}

Some instructors give extra credit for research participation. If your instructor does this, on the initial survey you can provide your name, the name and section of the class, and the instructors name. The instructor will give extra credit based on their class policies for research participation, allowing students who do not want to do research to have other opportunities for extra credit.

\section{Conflicts of Interest}

There is no conflict of interest presented in this study.

\section{Mandated Reporter}

We need to make you aware that in certain research studies, it is our legal and ethical responsibility to report [situations of child abuse, child neglect, or any life-threatening situation; illegal activity on the ISU campus, campus-controlled locations, or involving ISU students] to appropriate authorities. However, we are not seeking this type of information in our study nor will you be asked questions about these issues.

\section{Questions about the Research}

If you have any questions about the study, please contact the researcher, Desiree Hernandez (dhern18@ilstu.edu) or the supervising instructor, John Baldwin (jrbaldw@ilstu.edu). If you have any questions about your rights as a participant in this research, or if you feel you have been placed at risk, you can contact the Research Ethics \& Compliance Office at Illinois State University at (309) 438-5527.

You will be given a copy of this consent form for your records.

I consent to participating in the above study.

Signature

Date 


\section{APPENDIX D: DEMOGRPHICS QUESTIONNAIRE}

First, I am going to ask you to answer questions about yourself.

1. Pronouns:

2. Gender:

3. Age:

4. Race/Ethnicity:

5. Marital status:

6. Sexual orientation:

7. Length of time in romantic relationship with former partner:

8. Time since termination:

If you are seeking extra credit, please provide the following. Note that I will only inform your instructor of your participation; comments you make during the interview remain confidential.

Student name:

Name of instructor:

Course name:

Course number:

Section: 


\section{APPENDIX E: PARTICIPANT DEMOGRAPHICS}

\begin{tabular}{|c|c|c|c|c|c|c|c|}
\hline Participant & Age & Gender & $\begin{array}{c}\text { Race/ } \\
\text { Ethnicity }\end{array}$ & $\begin{array}{c}\text { Marital } \\
\text { Status }\end{array}$ & $\begin{array}{c}\text { Sexual } \\
\text { Orientation }\end{array}$ & $\begin{array}{c}\text { Romance } \\
\text { length }\end{array}$ & $\begin{array}{c}\text { Time since } \\
\text { termination }\end{array}$ \\
\hline Jan & 22 & Queer & Caucasian & Single & Queer & 25 months & 48 months \\
\hline Jackie & 19 & Female & Caucasian & Single & Straight & 6 months & 21 months \\
\hline Kylie & 19 & Female & Caucasian & Single & Straight & 36 months & 21 months \\
\hline Ingrid & 21 & Female & Caucasian & Single & Straight & 5.5 months & 30 months \\
\hline David & 30 & Male & Caucasian & Married & Straight & 6 months & 108 months \\
\hline Lisa & 31 & Female & Caucasian & Married & Straight & 24 months & 48 months \\
\hline Ava & 19 & Female & Asian & Single & Straight & 3 months & 14 months \\
\hline Don & 48 & Male & Caucasian & Married & Straight & 24 months & 264 months \\
\hline Megan & 21 & Female & Caucasian & Single & Straight & 12 months & 5 months \\
\hline Eddy & 19 & Male & Caucasian & Single & Straight & 5.5 months & 36 months \\
\hline Luke & 19 & Male & Caucasian & Single & Straight & 8 months & 24 months \\
\hline Mark & 22 & Male & Caucasian & Single & Straight & 3 months & 18 months \\
\hline Ivy & 20 & Non-binary & $\begin{array}{c}\text { Black/ } \\
\text { African }\end{array}$ & Single & Bisexual & 12 months & 48 months \\
& & & American & & & & \\
\hline
\end{tabular}




\section{APPENDIX F: INTERVIEW PROTOCOL}

Thank you for agreeing to participate in my study on platonic friendships between former significant others. Do you understand the informed consent form that I sent you via email? This is a voluntary interview, that means you can skip any questions that you do not want to answer or end the interview early. There is a chance that you risk losing confidentiality, but I will give you a pseudonym in the transcripts and protect the audio files on a private, password protected computer.

- What's your story on why you two ended up a couple?

- Can you tell me about significant moments during the break-up?

- What significant moments did you experience post break-up?

Thanks so much that gives me context into your situation. I'm interested in understanding movement from romantic relationships to platonic friends that people have with a former significant other. I'm hoping to continue our conversation by talking about turning points, and I'm going to continue to ask you about your relationship with your previous partner. A turning point is, "a transformative event that alters a relationship in some important way, either positively or negatively" (p. 294, Baxter, Braithwaite, \& Nicholson, 1999).

- Can you identify transformative events like turning points throughout your relationship with your previous partner? Tell me about them, what comes to mind?

- What turning points did you experience following a break-up to achieve a platonic relationship with a former significant other?

- Refer back to certain events and ask them to elaborate on them. You mentioned the break-up and dating new people, can you tell me more about these turning points?

- What turning points facilitated interaction between you and your ex?

- What were times when you felt closer or in more contact with your ex?

- What were times that hindered contact with your ex? Or times that created distance and made it harder to interact with them?

- Which of these interactions or turning points do you think facilitated or hindered your relationship with your previous partner?

- Which of these turning points do you think are positive, neutral, or negative?

- What else would you like me to know?

- When you contacted me about this study, what did you think we would talk about during this interview?

Possible probes:

- Alright, here is a list of turning points, as you look at this list tell me if you think it accurately describes what you just told me?

- In what ways were the turning points that you experienced positive for you as an individual, for the relationship, or positive for both or neither?

- In what ways were the turning points that you experienced negative for you as an individual, for the relationship, or negative for both or neither?

- In what ways were the turning points that you experienced neutral for you as an individual, for the relationship, or neutral for both or neither? 